\title{
Formal semantics and functional semantics
}

Peter Widell

Aarhus Universitet

Peter Harder

Københavns Universitet

\begin{abstract}
This joint article represents an attempt to clarify relations between two rather different approaches to the description of linguistic meaning: truthconditional semantics (as represented by Peter Widell) and functional semantics (as represented by Peter Harder). The two approaches are anchored in different traditions, are based on different theoretical premises, and have different objectives. Truth-conditional semantics is based on a philosophical tradition with strong relations to logic, while functional semantics is based on a linguistic tradition with borrowings from evolutionary biology (and also from speech acts philosophy). We argue that an integrated picture that accommodates both approaches can be achieved by a mutual recognition of the different aims as well as of a central area in which the different aims give rise to compatible insights about linguistic meaning.
\end{abstract}

\section{The formal approach}

\section{Introduction}

The concept of (linguistic) meaning remains difficult to explain and understand in a consensual way. Ever since antiquity it has been the subject of intensive inquiry. The most familiar and influential discussion is the one based on Plato's doctrine of ideas or forms, as mentioned for example in his Republic, book 7. Here, the view is expressed that the reason why we can use the word cow (our example) to refer to different cows is that

Ken Ramshøj Christensen, Henrik Jørgensen \& Johanna L. Wood (eds.). 2019.

The Sign of the V-Papers in Honour of Sten Vikner. Dept. of English, School of Communication \& Culture, Aarhus University, pp. 735-757, doi:10.7146/aul.348.122. (C) The author(s). 
all cows 'participate' (as Plato says) in the same cow-meaning (= idea or form). According to Plato, this entails that the idea must have independent existence apart from the different instantiations, in a realm of ideas beyond the world of sense impressions. A different proposal goes back to the empiricist philosopher John Locke, who suggests that the conceptual meaning of a word must be found as an idea or mental representation in the mind of the person who uses the word.

Many have been dissatisfied with both explanations, and proposals for alternatives have been put forward throughout the twentieth century. Two suggestions from the beginning of the century have been especially influential; both try to define their way out of the problems.

One is due to structuralism in the Saussurean tradition. The core idea is that linguistic meaning is viewed as a by-product of structural relations in the specific language to which the words and sentences belong, cf. Saussure (1983 [1916]). Meaning is thus defined in a purely language-immanent way as emerging from a system of differences between linguistic signs.

The other proposal we find within analytical philosophy. Here, meaning is defined with the help of logic, based on the concept of truth. (Conceptual) meaning is simply understood as those conditions in the world that make sentences in language true or false.

There are certain parallel views of the nature of language within the traditions of structuralism and analytical philosophy. For instance, the notion of 'implicit definition' in Hilbert (1899) and the syntactic understanding of logic in Rudolf Carnap (2000 [1934]) have striking similarities with the immanent view based on sign differences in Saussure. Nevertheless, there has been little interaction between the two sets of views - although in a Danish context, Hjelmslev tried (with unfortunate consequences, cf. Harder 1974) to introduce notions from logical positivism into his view of the foundations of linguistics, spurred on by parallel ideas about the autonomy of formal description.

In recent decades, however, the linguistic tradition has developed beyond the purely relational approach in classical structuralism. Internationally, this is manifested in cognitive linguistics (in the traditions of George Lakoff and Ronald Langacker), and in functionalist traditions of different types, including those of Dik (1989), Givón (1993), Foley \& Van Valin (1984) and others. Truth-conditional semantics has similarly expanded to include dimensions of meaning traditionally associated with the pragmatics of communication, cf. e.g. Sperber \& Wilson (1986), 
Carston (1988) and Recanati (1989) on semantic underdeterminacy of propositional content and Rooth (1992) on focus assignment.

In Denmark, there has been a development whereby certain key notions from European structuralism have been integrated in a functional approach to linguistic description (cf. Engberg-Pedersen et al. 1996). The move beyond classical structuralism consists, briefly speaking, in recognizing that meanings have a positive content - which enables them to function in communication - while also having structural relations between them. The positive content motivates both the speaker's choices (when she uses the word cow instead of horse, for instance), and also structural distinctions. The ancient assumption that the grammatical category of substantives reflected the metaphysical category of substances was proved wrong by structuralism, but there is a motivating relationship that goes in the other direction, cf. Lyons (1966): all physical objects like stone are denoted by nouns rather than verbs.

Some insights from structuralism continue to be valid, because structures cannot be fully derived from functional properties, and thus have a (partial) life of their own, cf. Harder (1999). The important point in this context is that language, in this approach as opposed to uncompromising structuralism, has relations with the world outside purely structural relations.

This has provided a footing on which it becomes possible to explore mutual relations between the two approaches in the title. This opportunity we would like to take in this article, with Peter Widell taking the perspective of formal semantics and Peter Harder the perspective of functional semantics. While this does not directly address the focal research interests of Sten Vikner, we hope that the discussion below will represent a contribution to the fruitful possibility of dialogue across disciplinary frontiers that is manifested in the broad scope of contributors to this volume.

Our main suggestion is that the two approaches to meaning do not directly contradict one another, but rather could be viewed as complementing one another by asking important but different questions about language and meaning. The focal concerns of the two approaches find their answers in different, but interconnected areas of language. While formal semantics takes its point of departure in truth conditions associated with the propositional core, functional semantics takes its point of departure in the communicative anchoring of linguistic signs in human interaction, ultimately drawing on evolutionary foundations. 
A word of warning: Because the point of the paper is to establish a platform on which the two approaches can meet, most of what is said about each of the two approaches below will be very fundamental. By purposely limiting ourselves to the basics, we hope to give an accessible view of the common playing field that is otherwise not easily discernible.

Although we focus on different analytic tasks, there is an essential meeting point in the form of the assertion. We see the assertion as the core functional category, which at the same time provides the setting for the proposition with its truth-based relation to the world, and also constitutes the key functional innovation of human language. Although assertive statements about what is the case are one among other types of functional contributions to human interaction as pointed out by Wittgenstein (1953), the capacity to interact by way of exchanging propositional information is an essential part of what makes human language unique. The account therefore aims to transcend the traditional association between 'function' and pre-linguistic relations (on the one hand) and 'logic' and purely formalmathematical aspects of meaning. Based on this recognition, Peter Widell (in the first half of the paper) will work from the assertion towards the proposition and its truth conditions, while Peter Harder (in the second half of the paper) will work from the assertion towards its links with interactive aspects of meaning.

\section{Formal semantics: Conceptual, linguistic meaning $=$ truth conditions}

Language is a means of communication. But it must also have an anchoring in the world: linguistic utterances have - as the basic, canonical case - to be TRUE of the facts we find in the world, and this assumption has to be a shared feature between participants in communicative events. Otherwise language would carry no valid meaning. That is the basic point of departure for the theory of meaning on which formal semantics builds.

Let us take an example of communication showing what is at stake: A watches his neighbour $\mathrm{C}$ felling a fir tree, and subsequently goes to speak to B, saying:

\section{(1) $C$ is felling a fir tree}

In this case, A's neighbour must have been engaged in this act (witnessed by A), as a condition of A's utterance being true. In that sense, the linguistic sign - the cited sentence - is related to a previously existing situation in the 
world. It is precisely this relation between situation and sentence which has been in focus for formal logic and which it is therefore concerned to (re)construct and provide with an explicit theoretical form. It is this task which has turned out to be in no way simple, on which we will concentrate below.

The German logician and philosopher Gottlob Frege, in his Begriffsschrift (1879) has suggested an interesting analogy (which he fully developed in an article from 1892) between a sentence like (1) and the mathematical notion of function, cf. (2):

(2) $y=f\left(x_{1}, x_{2}, \ldots\right)$,

In (2), $y$ corresponds to the sentence (1) $C$ is felling a fir tree while $x_{1}$ stands for the proper name " $C$ " referring to the individual object, in this case the person C. In turn, $x_{2}$ stands for a particular fir tree, and $f$ stands for the predicate " $[\ldots]$ is felling $[\ldots]$ ", which is ascribed to respectively $\mathrm{C}$ and the fir tree referred to in sentence $y$.

The analogy between the sentence and the mathematical function directly shows what is at stake in the sentence: the sentence $y$ is not merely a juxtaposition or concatenation of the expressions $f$ and the different $x$ 's, in the example the felling, $\mathrm{C}$ and the fir tree. The sentence expresses a judgement (Frege: Urteil) - i.e., a judgment that the object referred to by $C$ is included in the set of objects referred to by the predicate $f$ (of persons engaged in tree-felling). This in effect describes a kind of act: to ascribe a predicate $f$ to some $x$ 's in fact amounts to making an assertion.

The crucial point in Frege's analysis is that assertions are seen as being essential for bringing language into contact with the world and assigning meaning to it. Only when a judgment is made are linguistic sentences brought into contact with those facts in the world that they concern. And only then will it be possible for the proposition expressed by the sentence to be true. Language in its abstract form is not the most important thing about language - it is the actual use of it in concrete speech situations which enables it to express true or false propositions.

Some assertions, as in example (1) above, are simple, and their propositions can be true or false independently of other propositions. Others are complex assertions in which the truth values of the whole proposition can be systematically calculated by reference to the truth values of the simple propositions which they contain. In addition to discovering that the sentence can be seen as a function, Frege is acclaimed for having set 
up a complete set of rules for calculating the truth value of any complex proposition, given the truth values of the constituent's simple propositions. ${ }^{1}$ This system can be found in its full form in logic textbooks under the heading 'first-order predicate logic' ("first-order" because what logic needs to refer to in order to avoid paradoxes and contradictions, are things in the world, not expressions denoting those things).

Frege's predicate logic from 1879 is in all ways a masterpiece, which virtually all formal semanticists regard as the ultimate canon of logic. During the twentieth century, a succession of logical theories arose, but they are not alternatives to Fregean logic, but rather special applications of his system, which constitutes the only necessary foundational logical theory.

Besides 1879 another epoch-marking year is 1905, when Russell publishes his article "On Denoting". In it, he seeks to provide a more precise answer to what happens when we use a particular form of reference in language, the type expressed by what came to be known as definite descriptions like the capital of France. Russell's point about the use of such expressions is that although they are similar in function to proper names, they at the same time provide a description of their referent. Unlike Paris, which refers to the same city, the capital of France provides a description of the object to which it refers.

Russell believes that this leads to the possibility of contradictions. The problem is best known from the account given by the Austrian phenomenologist Lexius Meinong (1960 [1899]). The problem is that in accounting for statements such as The Golden Mountain does not exist it appears that they presuppose the existence of an object whose existence is subsequently denied. Meinong himself believes he has found a solution: There are two modes of existence, one for ordinary objects and one for impossible objects such as the Golden Mountain and the square circle; these have according to Meinong a mode of existence called "subsistence".

1 It would take us too far to introduce all the rules in Frege's set of rules. It is not our task here to engage in predicate logic. The rules for the so-called quantifiers should, however, be mentioned, namely the rule for use of the existential quantifier (indicated in bold): There exists an $\boldsymbol{x}$, such that $x$ is $P$, e.g. There exists an $x$, such that $x$ is a living creature, and the rule for use of the universal quantifier (indicated in bold): For all $x$, it is the case that $x$ is $P$, e.g. For all $x$, it is the case that $x$ is a human being. The reason for mentioning the rules is that they represent a simple and elegant completion of predicate logic by allowing multiple use of expressions like all and some, e.g. For all $x$ there exists a y, such that if $x$ is $P$, then $y$ is $Q$. From Aristotle to Kant and Mill logicians have lived in blissful ignorance of these rules. That is why logic in their hands has appeared like a torso. 
This solution Russell finds just as unsatisfactory as the problem it is meant to solve - it smacks of Platonic 'ideas' or 'forms'.

Instead, Russell points to a quite different take on the problem, one based on logical analysis. Traditionally the verb exist is viewed, based on grammatical criteria, as a predicate. But according to Russell this gives a distorted picture. "To exist" does not signify a predicate, but an existential quantifier (cf. note 1). This means that the sentence the Golden Mountain does not exist must be re-described as having the following logical form, in order to yield a proper description of its meaning: There exists an $x$, where $x$ is a mountain, and $x$ is golden [....]. Under this interpretation, one will avoid the problem of existence, and what emerges is simply a false sentence: There is something which is a mountain and is golden.

It is important to understand that Russell's solution does not merely apply to impossible examples like the Golden Mountain and square circles. The analysis is quite general and applies also to normal cases like the capital of France. In addition to existence, the logical form for definite descriptions also includes the 'uniqueness' aspect which distinguishes definite from indefinite descriptions (e.g., the capital of France from $\boldsymbol{a}$ capital of France), so that there can be only one referent answering to the description. A definite description can be paraphrased, there is an $x$ which is the Capital of France, and if any $y$ is the capital of France, then $y=x$.

The importance of this analysis for the subsequent philosophical discussion can hardly be overestimated. It is viewed not only as one of the first, but also one of the best examples of conceptual analysis in analytical philosophy, illustrating an important innovation in what doing philosophy means. What Russell's analysis shows is how to analyze any sentence in a way that factors out a purely referential element (a 'logical proper name') from the descriptive content (the predicate). According to Russell, the combination of these two constitutes the essential meeting place between syntax and semantics.

\section{Frege's necessary correction}

In 1892, i.e. more than ten years before "On Denoting", Frege publishes an article which puts into question the idea of logical proper names, i.e. proper names without descriptive/conceptual content. In contrast to what Russell argues in 1905, Frege claims that proper names always have descriptive content. In his argument Frege refers to various examples of proper names, including a now famous example from astronomy. The example goes: In 
ancient Mesopotamia two characteristic features of the night sky had been noticed. One star was always the first to light up after sunset (which was therefore called the Evening Star), while another star was always the last to be visible after sunrise (which was therefore called the Morning Star). The interesting thing was that it was at one point discovered that they were not stars at all, and only one heavenly body was involved, viz. the planet we now know as Venus.

The point of this example is that on closer inspection it appears to demonstrate that in spite of his sophisticated analysis of the proposition, Russell is actually wrong and Frege right. In the example we have one referent and two descriptions. Venus is present to us in one way in the evening and in another way in the morning. But such different 'ways of being given to us' (Frege: Art des Gegebenseins) are really omnipresent. For instance, an equilateral triangle can also be an 'equi-angular' triangle. And a block can both be a red block and a square block. This means that the division into a purely referential and a purely descriptive element according to Frege cannot solve the problem that Russell wants to solve. You could, as Russell does, argue that a proper name like the Evening Star has a hidden descriptive content and is actually also a definite description separating the referential and the descriptive element. But according to Frege even proper names without explicit descriptive content as for instance the proper name Paris has a sense according to Frege.

It is evident that Russell and Frege cannot both be right at the same time. There is, however, a way to solve the problem. Russell and Frege are not talking about the exact same thing (a fact under-emphasized in the philosophical discussion). Russell talks about language, about sentences and their component parts - while Frege basically is not talking about linguistic expressions at all. When Frege analyses propositions, he sometimes talks about statements, but when he talks in a more focused way, he instead talks about 'thoughts' (the German word is Gedanke). The point is that thoughts do not have to be expressed by a linguistic sentence. Frege points this out rather explicitly in a late article, precisely entitled $\mathrm{Der}$ Gedanke. Here he writes:

We may distinguish: 1. the apprehension of a thought - thinking; 2 . the recognition of the truth of a thought-judgment; 3. the manifestation of this judgment - assertion (Frege 2008 [1918-1919]: 39). 
Hence, Frege marks a difference between the thought and the expression of the thought. Elsewhere in the article he writes, "How does a thought act? By being apprehended and taken to be true. This is a process in the inner world of a thinker (...)" (Frege 2008 [1918-1919]: 48). In other words: For a thought to get expressed by means of language is coincidental. The 'way of being given' is not in the words, but in the thought itself.

This is not to deny that certain more complex thoughts necessarily have to piggyback on linguistic formulations. But it means that thoughts are inherently capable of coming into being independently of language, and also that speech in its early stages probably borrows all of its substance - its empirical content - purely from our state of relatedness to the world through perception, thinking and action (cf. Makin (2000) for a comment on that). To return to Frege's most famous example: Our awareness of the Evening Star is throughout based on that particular 'way of being given' that consists in our perceiving it as a feature of the evening sky.

This perspective is clearly different from that of linguistic semantics. In the radical structuralist version of Saussure as understood by Hjelmslev's 'Copenhagen School', linguistic meaning was assumed to come into being by the combination of a linguistic expression (signifiant) and a conceptual meaning (signifié) - as organized in an autonomous, immanent linguistic system. In contrast, as we can see, according to Frege, the basis for meaning as expressed in language is an awareness based only on perception and action. This awareness is also reflected in our understanding of referential expressions, including proper names.

It is true that forms of (perceptual and actional) practice, represented in the ways of givenness through which the world presents itself to us, get incorporated in the sign systems that languages constitute. But that is not the same as saying that sign systems are constitutive of meaning, understood as our awareness of or relationship with the world. Language comes afterwards, as a post-hoc phenomenon. This means that linguistic expressions at the basic level are precisely what Saussure denied (Saussure 1983 [1916]: 75): purely labels for externally given meanings, rather than autonomous entities.

Russell's concept of 'logical proper names' as being purely referential expressions is valid only as a theoretical, formal construction - an operation in a logical calculus with no conceptual content. If thoughts are to have conceptual substance, they must reflect the world as it presents itself to us in perception and action. That is what Frege's theory of 'the thought' has taught us: The thought is not a linguistic construct. Thoughts are basically 
constituted by our awareness of the world as it presents itself to us in perception and action.

Unfortunately, Frege views his thoughts as part of an objective 'third realm' besides the empirical world, which is reminiscent of Plato's world of ideas. Frege's motivation for this is his desire to avoid 'psychologism', i.e. the view that thoughts and logic are subject to the vagaries of the empirical world. As a response to psychologism, this appears, however, to be an extreme reaction. To conceive of logic as an empirical process is of course not appropriate. But instead of setting up an ideal world apart from the world of the senses, we can take our point of departure in what may be called 'normative phenomenology'. Essential from this point of view is the realization that human awareness as based on perception and action contains an inherently reflexive aspect. What this entails can be spelled out in the form of 'principles' or 'maxims' that underlie, or are taken for granted, in the way we understand the empirical world.

The level at which such principles belong has been addressed in various ways through the history of philosophy (e.g., by Kant, Heidegger, Grice and Habermas), and it would take us beyond the scope of this paper to discuss it further here. ${ }^{2}$ For the purposes of the argument above, the following three principles are basic:

\section{WE ACT IN THE AWARENESS THAT WE CAN DO THINGS RIGHT OR WRONG IN RELATION TO OUR INTENTIONS}

(the normative point of departure)

\section{GOAL-DIRECTED ACTION REQUIRES KNOWLEDGE OF THE CAUSAL STRUCTURE OF THE WORLD \\ (causal prerequisites as criteria of appropriate action)}

\section{INFORMATION ABOUT THE WORLD IS AVAILABLE VIA PERCEPTION, PROVIDING 'WAYS OF GIVENNESS'}

(truth can be assessed and structured via reference and predication)

All this we have to presuppose as a necessary part of our 'being-in-the world'. A house can be viewed from different directions - but this does not mean that the house itself is merely the sum of these perspectives. Rather, based on our co-ordination of these perspectives, the causally accessible world is gradually appearing as an objective reality - as Venus has come

2 For a more extensive discussion of some of these matters cf. Widell (2009). 
to be the objective astronomical object it is, as a result of co-ordinating the evening and the morning perspectives ('ways of givenness').

All this presupposes perception - otherwise we would act 'blindly' (which really means not being able to act at all). But action additionally presupposes the organisation of information so as to make reference and predication possible, thus enabling the assessment of truth. And finally, the link with meaning as related to language arises when we take the step towards assertion, communicating propositions (based on thoughts) as being true.

At this point, via the crucial link of assertion, meanings enter into the realm of linguistic conventions. Such conventions, as organized into a language system, are what enables us to build up and share all the specific conceptual meanings as part of the complex interactional processes that depend essentially on the availability of meanings that are not always directly anchored in perceptions 'as they are given to us'.

\section{Functional semantics}

\section{The assertion in an evolutionary context}

The assertion also has a crucial status in a functional perspective, if functionality is viewed in the context of an evolutionary pattern of thinking - as it must be, in a modern version of functionalism. To show why this is so requires a number of steps, beginning with an account of what is meant by the term 'functional'.

As pointed out above, functional semantics differs from semantics as conceived within the Saussurean, structuralist paradigm, by taking its point of departure in what speakers can do with language - hence also in a perspective which sees language as anchored in a wider world beyond language itself. It also differs from the purely cognitive perspective on semantics, in which the human mind is viewed as the sole and privileged context in which language belongs. This is not to say that the functional perspective does not view language as belonging in a cognitive context rather, it views also cognition as belonging in a wider, functional context.

Functionalism in an informal, intuitive sense has been part of linguistics since Aristotle. However, while the tradition from Aristotle could allow itself to assume that things in nature had inherent functions (so that one could explain the presence of sharp teeth in a lion by reference to the fact that it was a beast of prey), this assumption is untenable in a modern scientific world view. 
In an evolutionary perspective, functions arise, cf. Wright (1973), when an organ or tool has causal powers (effects) that contribute to keeping the system to which it belongs in existence. With the beast of prey example, sharp teeth contribute by enabling the lion to kill its prey, thereby allowing it to survive and reproduce. This in turn ensures that there will be lions around also in the next generation. It is this two-step causal relationship that qualifies as a definition of 'function' that can play a role in scientific explanations of how biological features can arise, cf. also Allen, Bekoff \& Lauder (1998).

Note that this double causality is not limited to biological entities. It also applies to artefacts, e.g. screwdrivers: they contribute to human practices by making it possible to have objects around that need to be fixed by screws, and this in turn is what makes us keep screwdrivers around.

Teeth from beasts of prey also have other uses, e.g. as means of payment, but that is not what keeps beasts of prey in business, hence not what causes the teeth themselves to be reproduced from generation to generation. Thus the function of an object (in this privileged evolutionary sense of the word) is not just any effect or causal power - only that which contributes to reproducing the system of which it forms part from generation to generation. Hence, functions depend on a complex causal relation that can only arise in systems that depend on reproduction for their continued existence. The Atlantic Ocean therefore does not have a function in the evolutionary sense - it just stays around, whatever uses it may have.

How this view of functions applies to language in general is a question that cannot be addressed here, but cf. Harder (1996); only a few crucial applications can be pointed out. One concerns the question of whether the function of language is essentially to do with communication or with the structuring of thought - an issue that has tended to divide the generative from the functionalist camp, cf. Givón (1993), Jackendoff (1994), Knight et al. (2000).

The combined approach in this paper illustrates why this is a pseudoquestion. The question of whether thought or communication is most essential presupposes that the two are necessarily in competition; but there is no reason to assume that it is not a combination of both. Starting from the functional perspective, we can say that whatever the functional role of thought may be in relation to language, in terms of the approach to function described above there can be no serious discussion about whether communication is crucial. Language could not be a feature of the human world unless it was transmitted from generation to generation via 
communication. Regardless of the contribution of genetic factors, no one to our knowledge has claimed that language acquisition would be possible without linguistic communication, cf. Harder (1996: 99).

Having established that communication is necessary to keep languages around, let us turn to the role of thoughts. If we view human languages in the context of evolutionary history, after attempts to establish continuity between animal and human communication (cf. Pinker 1994), it has become generally accepted that there remains a clear break between human linguistic abilities and those of even the most successful trained apes. For the purposes of this paper, we shall point to two aspects of what this break consists in.

One aspect is the rise of context-independent, mental meanings. Prehuman forms of communication, cf. Deacon (1997), are anchored directly in the situational environment, and human languages are thus unique in possessing purely symbolic, situation-detachable meanings. Thus alarm calls, cf. Cheney and Seyfarth (1992), are triggered by a danger (e.g., a leopard), present in the situation - not by a leopard that is only part of the sender's mental world. With a rough but illustrative exaggeration, this makes animal communication in principle subject to stimulus control, thus potentially to a behaviourist approach. Meanings in such systems of communication are basically in the environment, not in the mind.

Human languages, in contrast, are distinguished by the presence of purely mental, i.e. conceptual meanings, distilled from but not directly triggered by relations with the environment (along with surviving features shared with animal calls, e.g. ouch as an expression of immediate pain). The meaning of the word leopard is not inherently associated with a situationally present specimen. The rise of conceptual meaning is thus part of the history of evolution. Before a certain point in evolution, meanings of the kind that are characteristic of human languages did not exist.

If we go back to the role of thoughts in Frege's account, evolutionary history can thus offer to supply the background. Before the rise of the ability to entertain meanings independently of direct environmental triggers, it would not be possible to operate with the core elements in his theory, including the formation of thoughts that could be evaluated as either true or false: a false thought must by definition be one without something to match it in the environment.

While purely mental meanings are necessary to enable the formation of thoughts in the sense assumed by the tradition, including Frege, they are not in themselves sufficient. An inventory of concepts including for 
instance leopard, kill, and prey would not in itself contain anything that could be either true or false. We also need to combine these meanings into thoughts with assertible content and describe what role such assertible thoughts may have in the human world. We therefore need to look at the second aspect of the crucial evolutionary step forward that is associated with human language.

This step was described by Tomasello (2008) as involving the capacity for joint attention and action. This capacity involves a number of things, cf. Harder (2010: 75f), but especially it requires that human beings can relate to each other in two ways: (1) by attending to the same thing; (2) by attending to it not because of its inherent interest from a purely individual point of view, but because of the interest it gets by virtue of human subjects attending to it together.

This sense of 'togetherness' creates a new status for the object of attention - and this may also cause people to persist even in activities with no apparent goal (Tomasello 2008: 177-78). This engagement in 'being in this together' goes with a species-specific form of altruistic orientation, cf. Warneken \& Tomasello (2006), towards shared rather than purely individual access to environmental affordances.

What this means is that human beings are unique in finding it worthwhile to share thoughts with no immediate environmental payoff. With this, we are back at the crucial status of the assertion. The assertion is the basic formula that allows the formation of complex meanings that constitute communicated thoughts.

The appropriateness of this contextualization of assertions as a design feature of human communication can be supported by reference to the finding that one thing that language-trained apes have never been recorded as doing spontaneously is to produce purely declarative, assertive statements. In a pre-human world it is not obvious what enhanced selective fitness would be achieved by providing unsolicited information for free. From the recipient's perspective, in terms of the pre-human animal world there is no apparent role for paying attention to what fellow subjects might want to say about the world - no way for it to be ecologically appropriate to make such utterances. Only in the human world where 'being in it together' has a value in itself does it make sense to share your thoughts. Tomasello has produced a wealth of experimental evidence illustrating this feature of human interaction (examples can be found on YouTube!). 


\section{The evolutionary rise of content substance}

Assertions, as pointed out above, depend on structuring and combining human, conceptual meanings in particular ways. From the point of view of linguistic semantics, this raises the question of how this evolutionarily and philosophically central type of complex sign fits into a general theory of meaning as a property of language.

Some basic features can be illustrated by going back to the primeval stage of the rise of human languages. This rise of conventional meaning must involve a basic step by which certain overt actions (which may have been gestural rather than vocal at the first stage, cf. Tomasello (2008)) became associated with a content that made it relevant to re-use particular actions for conveying that particular content. This instantiates the two-step causal relation associated with evolutionary functions: the effect of using such a sign is what causes speakers to reproduce utterances of which they form part. When this happens, languages can arise and persist by the same causal mechanism that drives other evolutionary processes.

But we may follow the pathway stipulated by Frege in arguing that this step must be preceded by an even more fundamental step, which is directly linked to the rise of joint attention and action: Before signs can come into being, there must be shared, communicable meaning. It makes no sense to try to invoke a kind of meaning that is not available to the designated addressees. Where animal signals or calls can rely for their efficacy on a shared environment, signs with conceptual meaning can only operate in an environment where there is already an emerging pool of shared conceptual meaning.

From this it follows that at the pre-linguistic stage of language phylogeny, shared attention and action must have engendered a resource of jointly available mental content among members of the pioneer community. In the pre-human world, individuals can possess a rich mental world but such mental worlds are strictly private; a pool of shareable meaning is a new evolutionary phenomenon. As discussed above, Frege posits a quasi-Platonic 'third realm' to provide a location for meanings, in order to avoid the vagaries of individual empirical psychology. In the picture outlined here, what underpins the status of meanings as being irreducible to individual psychology is not a realm of ideas, but the presence of shared, co-ordinated meaning creation in the community. It is the obligatory embedding of meaning in a shared set of norms that underpins the "normative phenomenology' described above. Content substance constitutes meaning 
that is endowed with human communicability, and thus available for potential encoding, but viewed in abstraction from particular alternative ways of communicating it by means of linguistic signs.

Like all evolutionary innovations, content substance is not wholly new - it piggybacks on what was there before, i.e. individual mental content. But the innovative step from individual to shared content is essential for human languages to arise - with the word cow as an example, unless we could entertain the meaning 'cow' as a shared idea, human language would not be viable as an evolutionary innovation. Moreover, once we possess a universe of shared meaning, it can accommodate semantic material that could not arise via the royal road of individual perception and action, including the meanings of words like unicorn, phlogiston and quidditch.

The role of sharedness as opposed to direct relations with the surrounding world also for quite mundane types of meanings can be illustrated by the way one learned to find one's way round the Nicaraguan capital Managua in 1997. At the time, all directions were given by reference to a point of orientation called 'the yellow cinema', a choice which was rather opaque for newcomers, since the cinema in question had been swallowed up by the ground in a major earthquake several years previously. But once familiar with the site on which it had stood, newcomers learned to adapt their geographical orientation around the yellow cinema, too.

The functional point of view agrees with the formal point of view that meaning is not inherent in the linguistic sign (pace the Saussurean tradition). But unlike the referential tradition, functionalism assigns an essential role to human subjects in the picture. It is because human subjects have evolved to understand the world in particular ways, and do it as a community rather than as individuals, that not purely individual and idiosyncratic meaning becomes available - and hence offers the possibility of conventionalization. Without the previous rise of content substance, conventional linguistic meanings would not be conceivable.

\section{Assertions in a functional and structural perspective}

As the last point in this discussion of where referential and functional semantics meet, we shall now offer what can only be a very sketchy account of the way assertions, as a key issue, are intertwined in a semantics based on linguistic structure.

We saw above that functional linguistics, like referential semantics, differed from the Saussurean tradition in viewing meaning as anchored in the world outside language itself. While a functional approach is sometimes 
viewed as antithetical to a structural approach, the Danish (and also more generally the European) functional tradition is based on the assumption that structures are function-based. This means that we can only understand how complex linguistic signs are structured if we simultaneously understand what functions individual elements have in relation to each other as well as in relation to the communication of which they form part.

In a strand of the European tradition, cf. Foley \& Van Valin (1984), Dik (1989), Harder (1996), Engberg-Pedersen et al. (2005), Hengeveld \& Mackenzie (2008), Engberg-Pedersen et al. (2019) clause structure has been analysed in terms of the so-called 'layered structure'. This model constitutes a hierarchical organization of meanings of different types and embodies important cross-linguistic regularities that have counterparts also in generative linguistics, cf. Siewierska (1992). A key feature is that this hierarchy is broadly divisible, cf. Searle (1969: 122) into a formula for speech acts $\mathrm{F}(\mathrm{R}, \mathrm{P})$, with an illocutionary force taking scope over a proposition that is constituted by a referential and a predicational part. The difference is that a whole range of other linguistic expressions and categories provide differentiated microstructure around this major division.

Not all utterance meanings reflect this structure. An important exception is the type of utterances that constitute whole interactive acts, e.g., greetings like hello and exclamations like hurrah! Their meanings consist in acts that feed directly into human interaction without involving propositional content. Hence, they are not obviously addressable in terms of formal, referential semantics; they have no obvious 'thought content'. This should not unduly perturb proponents of the referential approach. Such acts, while being conveyed by conventional human signs, may be regarded as marginal when it comes to the design features of human language - although they enter into human languages, they are analogous to signals in animal communication by virtue of their direct links with the ongoing situational interaction.

Assertions, however, do reflect this structural division, also in a linguistic analysis: They have a propositional core, divisible into a referential and a predicational subpart - and they also, at the top of the hierarchy, involve what Frege calls a 'judgment'. In terms of the tradition of functional linguistics, this judgment belongs in a structural slot designated for illocutionary operators.

In the linguistic tradition, the meanings of these operators have to be pared down to what is strictly conventional, which creates a difference with the philosophical sense of 'illocution', cf. Engberg-Pedersen et al. (2019: 
270). Thus, an assertion in the structural-linguistic sense corresponds to what is traditionally called the 'declarative'. This means that it is not necessarily very assertive, but may also have more tentative readings. The similarity, however, is strong enough to justify the claim that there is an essential relation; there is a paradigmatic relation between declaratives and interrogatives, as exemplified in the pair he is coming/is he coming? such that the declarative conveys a commitment to the truth of the proposition, while the interrogative does not. Thus, we may assume that a Fregean 'judgment' is conventionally encoded by means of the declarative operator (signalled, in the example, by means of constituent order).

Also, we may choose to regard the two elements of propositional meaning, reference and predication, as inherently functional (propositional acts, in Searle's terminology, cf. Searle (1969: 24), and also in the linguistic tradition, cf. Hengeveld and Mackenzie (2008). Reference, as recognized since Strawson (1950), is a function that we may achieve by means of linguistic expressions, and only if that function is achieved, is the relation with the referent established.

Under this interpretation, functional clause structure can thus naturally accommodate the elements that are essential in a Fregean truth-conditional semantics. In addition, a functional analysis can throw additional light on the structural build-up of assertions, understood in this context as complex linguistic signs rather than un-encoded thought content.

What is more, the specifically referential properties of linguistic expressions need to be supported by semantic properties that are not in themselves referential, also in order to account for their role in bringing about assertions. I have argued elsewhere, cf. Harder $(1976,2009)$ that definiteness can be illuminatingly captured in an analysis that highlights the functional-interactive dimension of meaning. If we consider definiteness as constituting the meaning of the definite article the, we can use it to illustrate what a functional semantics can add to Russell's referenceoriented description.

Under this approach, what the (as opposed to the indefinite article $a$ ) conventionally signals is an interactive instruction to identify a particular referent as being talked about. If you say give me the book!, the addressee has not complied with the instruction unless he has identified the right book - in contrast to what is the case if the indefinite article had been used, as in a book. This is fully compatible with Russell's (1905) theory, because identification implies pointing to the one and only object for 
which the phrase the book stands. The conventional meaning ascribed to the definite article in this analysis stands directly on the shoulders of 'joint attention' as a crucial evolutionary innovation. Only speakers possessing this capacity can meaningfully ask each other to enter into a relationship of joint attention to a particular referent in order to share information about it.

Russell's analysis captures the referential aspect and its entanglement with the existence-and-uniqueness implications, as well as the falseness (the lack of fit with the real world) of statements about the Golden Mountain. What it does not capture is the interactive weirdness of statements about non-existing objects (as opposed to statements denying or asserting their existence). That weirdness emerges straightforwardly from assuming that the encodes an instruction-to-identify (and hence the whole presuppositional aspect): asking people to do something with a nonexisting object (whether to identify, to fetch, or to destroy it, etc.) is clearly deviant.

This interactive link is essential to create an actual assertion with a truth value. You cannot tell whether the book is illustrated in colour is true or false, unless you have identified the book in question. This identification is an interactive operation which cannot be captured in terms of what the world is like. It is neither a thought nor a constituent of a thought, but an act that anchors the thought to the world to which it applies. At the next level, going upwards from the structure of a referring expression to the role of reference itself, reference along with predication and assertion can be anchored in structural-functional account of how conventional meanings hang together. The functional and structural dimensions do not contradict the formal-semantic description, but provide it with a context that is beyond its own focal area of interest.

\section{Summary and final comments}

We have tried to argue that there are significant overlapping elements in the two approaches to meaning, and that the essential difference between them lies in what the aim of the description is. While the formal-semantic, truth-conditional tradition aims to account for meaning in relation to the world that statements are about, functional (-structural) semantics aims to describe meaning as a property of human languages. Both approaches go beyond structuralism in accounting for meaning as part of a wider world beyond the language system itself. In truth-conditional semantics, the essential relations with the surrounding world are reference and truth; 
in functional semantics, the essential relation is the function linguistic expressions have in enabling shared conceptualization between speakers as part of maintaining interactive relations.

Some elements of human languages fall outside the scope of truthconditional semantics, because they are not essentially concerned with propositional meanings that can be assigned a truth value. However, these holophrastic elements (hello, hurrah!, fuck!) are arguably not central to what human languages are about.

Other, more interesting elements (the examples are 'declarative' and definiteness) cannot in themselves be captured fully by their truthconditional properties. However, they have an essential role in accounting for how assertions - the truth-conditionally central type of utterances come to apply to those situations in the world that they are about. The 'judgment' that is central to Fregean semantics fits into a functional semantics in which we have illocutionary meanings at the top of the hierarchy, in the periphery above the central proposition: reference and predication constitute functions that if achieved, bring about the proposition that constitutes the content of the assertion; and finally, definiteness is an interactive signal that requires the addressee to bring about the referential relationship without which truth values cannot be assigned.

The semantic properties that are fundamental to truth-conditional semantics can thus without contradiction be fitted into a structuralfunctional semantics, where they enter into paradigmatic relations (assertion $\sim$ declarative has a paradigmatic opposition to the interrogative, and definiteness has a paradigmatic opposition to indefiniteness) and syntagmatic relations (e.g., with operators such as discourse markers) that are not essential to the concerns of truth-conditional semantics.

Just as a referential semantics cannot account for the whole area of linguistic semantics, a linguistic semantics cannot account for those parts of referential semantics that apply to features independent of linguistic coding. The use of formal, logical semantics as a skeleton structure underlying mathematical structure lies outside the purview of linguistic semantics. But if there is clarity both about the areas of overlap and the areas of divergence, an integrated perspective on the two approaches can enrich our understanding of the role and nature of conceptual meaning. 


\section{References}

Allen, Colin, Marc Bekoff \& George Lauder (eds.). 1998. Nature's purposes: Analyses of function and design in biology. Cambridge, MA: MIT Press. doi:10.1086/394129.

Boye, Kasper. 2010. Reference and clausal perception-verb complements. Linguistics 48, 2. 391-430. doi:10.1515/ling.2010.013.

Carnap, Rudolph. 2000 [German 1934]. Logical syntax of language. Abingdon, New York: Routledge. doi:10.1007/978-3-662-25375-5.

Carston, Robin. 1988. Implicature, explicature and truth-theoretic semantics. In Ruth Kempson (ed.) Mental representations: The interface between language and reality. 155-81. Cambridge: Cambridge University Press.

Cheney, Dorothy L.\& Richard M. Seyfarth. 1992. Précis of how monkeys see the world. Behavioral and Brain Sciences 15. 135-182. doi:10.1017/ s0140525x00067911.

Chomsky, Noam. 1986. Knowledge of language: Its nature, origin, and use. New York: Praeger. doi:10.2307/2185417.

Deacon, Terrence. 1997. The symbolic species. The co-evolution of language and the human brain. Harmondsworth: Penguin. doi:10.1075/eoc.2.1.08arm.

Dik, Simon C. 1989. The theory of functional grammar. Vol 1: The structure of the clause. Dordrecht: Foris.

Engberg-Pedersen Elisabeth, Michael Fortescue, Peter Harder, Lisbeth Falster Jakobsen \& Lars Heltoft (eds). 1996. Content, expression and structure. Studies in Danish functional grammar. Amsterdam/Philadelphia: John Benjamins. doi:10.1075/slcs.29.

Engberg-Pedersen, Elisabeth, Michael Fortescue, Peter Harder, Lars Heltoft, Michael Herslund \& Lisbeth Falster Jakobsen. 2005. Dansk Funktionel Lingvistik - en helhedsforståelse af forholdet mellem sprogstruktur, sprogbrug og kognition. Københavns Universitet \& RUC: København.

Engberg-Pedersen, Elisabeth, Kasper Boye \& Peter Harder. 2019. Semantik. København: Samfundslitteratur. doi:10.7146/nys.v34i34-35.13459.

Foley, William A. \& Robert D. Van Valin. 1984. Functional syntax and universal grammar. Cambridge: Cambridge University Press. doi:10.1017/ s0022226700010689.

Frege, Gottlob. 1879. Begriffsschrift, eine der arithmetischen nachgebildete Formelsprache des reinen Denkens. Halle: L. Nebert. doi:10.1515/9783110853933.19.

Frege, Gottlob. 2008 [German 1892]. On Sense and nominatum. In A.P. Martinich (ed.) The philosophy of language, 5th edn. 217-229. New York, Oxford: Oxford University Press.

Frege, Gottlob. 2008 [German 1918-19]. The thought: A logical inquiry. In A.P. Martinich (ed.) The Philosophy of Language, 5th edn. 36-49. New York, Oxford: Oxford University Press. 
Givón, Talmy. 1993. English grammar. A function-based introduction. Amsterdam: John Benjamins. doi:10.1075/z.engram1.

Harder, Peter. 1974. Videnskabelighed og hensigtsmæssighed - en metodisk uklarhed i det glossematiske begrebsapparat. PAPIR I, 3. 4-17.

Harder, Peter. 1976. En strukturel og funktionel beskrivelse af bestemthed i moderne engelsk. [University of Copenhagen unpublished M.A. thesis,].

Harder, Peter. 1996. Functional semantics. A theory of meaning, structure and tense in English. (Trends in Linguistics. Studies and Monographs 87). Berlin: Mouton de Gruyter. doi:10.1515/9783110818758.

Harder, Peter. 1999. Partial autonomy. Ontology and methodology in cognitive linguistics. In Theo Janssen \& Gisela Redeker (eds.), Cognitive linguistics: Foundations, scope and methodology, 195-222. Berlin/New York: Mouton de Gruyter. doi:10.1515/9783110803464.195.

Harder, Peter. 2010. Meaning in Mind and Society. A Functional Contribution to the Social Turn in Cognitive Linguistics. Berlin/New York: Mouton de Gruyter. doi:10.1515/9783110216059.

Hengeveld, Kees \& J. Lachlan Mackenzie. 2008. Functional discourse grammar: A Typologically-based theory of language structure. Oxford: University Press. doi:10.14198/elua2009.23.18.

Hilbert, David. 1899. Grundlagen der geometrie, Leipzig: Teubner. An English translation of the 10th edition is available as Foundations of Geometry, Leo Unger (trans.), La Salle, IL: Open Court Press, 1971. doi:10.1007/978-3-32292726-2.

Jackendoff, Ray. 1994. Patterns in the mind. New York: Basic Books.

Knight, Chris, Michael Studdert-Kennedy \& James R. Hurford. Language: A Darwinian adaptation? In Chris Knight, Michael Studdert-Kennedy \& James R. Hurford (eds.). 2000. The evolutionary emergence of language: Social function and the origins of linguistic form. 1-15. Cambridge: Cambridge University Press. doi:10.1017/cbo9780511606441.001.

Locke, John. 1690 [2014]. An essay concerning human understanding. Ware, Hertfordshire: Wordsworth. doi:10.1093/oseo/instance.00018020.

Lyons, John. 1966. Towards a 'notional' theory of the 'parts of speech'. Journal of Linguistics 2, 2: 209-236. doi:10.1017/s0022226700001511.

Makin, Gideon. 2000. The metaphysicians of meaning: Russell and Frege on sense and denotation. London, New York: Routledge.

Meinong, A 1960 [1899] The theory of objects. In Roderick Chisholm, (ed.). Realism and the background of phenomenology, Glencoe, Ill: Free Press.

Pinker, Steven. 1994. The language instinct, New York: Perennial Classics.

Plato. 2007 [around 380 BC]. The republic. London: Penguin.

Recanati, Francois. 1989. The pragmatics of what is said. Mind and Language 4. 295-329. doi:10.1111/j.1468-0017.1989.tb00258.x. 
Rooth, Mats. 1992. A theory of focus interpretation. Natural Language Semantics 1. 75-116. doi:10.1007/bf02342617.

Russell, Bertrand. 2008 [1905]. On denoting. Mind, New Series Vol 14, No. 56. 479-493. Reprinted in A.P. Martinich (ed.) The philosophy of language, 5th edn. New York, Oxford: Oxford University Press. 230-238.

Saussure, Ferdinand de. 1983 [1916]. Course in general linguistics. London, New York; Bloomsbury Academic.

Searle, John R. 1969. Speech acts: An essay in the philosophy of language. Cambridge: Cambridge University Press. doi:10.1007/978-3-658-13213-2_61.

Siewierska, Anna.1992. Layers in FG and GB. In Michael Fortescue, Peter Harder \& Lars Kristoffersen (eds.). Layered structure and reference in a functional perspective. 409-432. Amsterdam: John Benjamins. doi:10.1075/pbns.23.18sie.

Sperber, Dan. \& Deirdre Wilson. 1986/95. Relevance: Communication and cognition. Oxford: Blackwell.

Strawson, Peter Fredrick 1950. On referring. Mind, 59. 320-344.

Tomasello, Michael. 2008. Origins of human communication. Cambridge, MA: MIT press. doi:10.7551/mitpress/7551.001.0001.

Warneken, Felix \& Michael Tomasello. 2006. Altruistic helping in human infants and young chimpanzees. Science, 311. 1301-1303.

Widell, Peter. 2009. Logik, mening, handling og tale. In Inger Schoonderbeek Hansen \& Peter Widell (red.) 12. Møde om Udforskningen af Dansk Sprog. 295-312. Århus Universitet: Århus 2009. (draft in English: Logic, meaning, action and speech. http://peterwidell.com/tekster/index.html).

Wittgenstein, Ludwig (1971 [1953]). Filosofiske Undersøgelser. København: Munksgaard.

Wright, Larry. 1973. Functions. The Philosophical Review, Vol. LXXXII, 2. 136168. doi:10.2307/2183766. 